\title{
Article \\ End-Tidal Carbon Dioxide Pressure Measurement after Prolonged Inspiratory Time Gives a Good Estimation of the Arterial Carbon Dioxide Pressure in Mechanically Ventilated Patients
}

\author{
Arthur Salomé ${ }^{1,2,3}$, Annabelle Stoclin ${ }^{3}$, Cyrus Motamed ${ }^{4}\left(\mathbb{D}\right.$, Philippe Sitbon ${ }^{4}$ and Jean-Louis Bourgain ${ }^{4, *}$ (C)

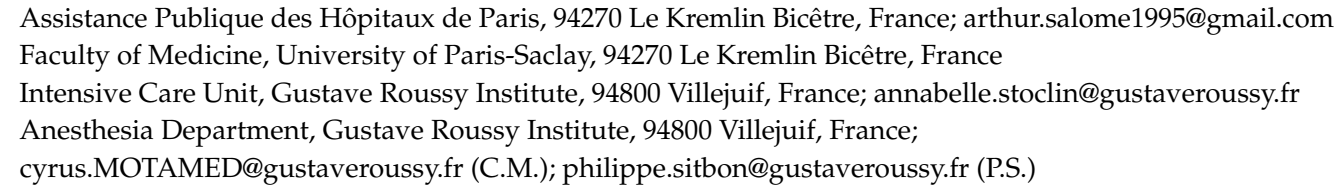

Citation: Salomé, A.; Stoclin, A.; Motamed, C.; Sitbon, P.; Bourgain, J.-L. End-Tidal Carbon Dioxide Pressure Measurement after Prolonged Inspiratory Time Gives a Good Estimation of the Arterial Carbon Dioxide Pressure in Mechanically Ventilated Patients. Diagnostics 2021, 11, 2219. https://doi.org/10.3390/ diagnostics11122219

Academic Editor: Anna Baraniak

Received: 4 November 2021

Accepted: 24 November 2021

Published: 27 November 2021

Publisher's Note: MDPI stays neutral with regard to jurisdictional claims in published maps and institutional affiliations.

Copyright: (C) 2021 by the authors. Licensee MDPI, Basel, Switzerland. This article is an open access article distributed under the terms and conditions of the Creative Commons Attribution (CC BY) license (https:/ / creativecommons.org/licenses/by/ $4.0 /)$.

\begin{abstract}
Background: End-tidal carbon dioxide pressure $\left(\mathrm{PetCO}_{2}\right)$ is unreliable for monitoring $\mathrm{PaCO}_{2}$ in several conditions because of the unpredictable value of the $\mathrm{PaCO}_{2}-\mathrm{PetCO}_{2}$ gradient. We hypothesised that increasing both the end-inspiratory pause and the expiratory time would reduce this gradient in patients ventilated for COVID-19 with Acute Respiratory Distress Syndrome and in patients anaesthetised for surgery. Methods: On the occasion of an arterial blood gas sample, an extension in inspiratory pause was carried out either by recruitment manoeuvre or by extending the end-inspiratory pause to $10 \mathrm{~s}$. The end-expired $\mathrm{PCO}_{2}$ was measured (expiratory time: $4 \mathrm{~s}$ ) after this manoeuvre $\left(\mathrm{PACO}_{2}\right)$ in comparison with the PetCO $\mathrm{C}_{2}$ measured by the monitor. We analysed $67 \Delta(\mathrm{a}-$ et) $\mathrm{CO}_{2}, \Delta(\mathrm{a}-\mathrm{A}) \mathrm{CO}_{2}$ pairs for 7 patients in the COVID group and for 27 patients in the anaesthesia group. Results are expressed as mean \pm standard deviation. Results: Prolongation of the inspiratory pause significantly reduced $\mathrm{PaCO}_{2}-\mathrm{PetCO}_{2}$ gradients from $11 \pm 5.7$ and $5.7 \pm 3.4 \mathrm{~mm} \mathrm{Hg}(p<0.001)$ to $\mathrm{PaCO}_{2}-\mathrm{PACO}_{2}$ gradients of $-1.2 \pm 3.3(p=0.043)$ and $-1.9 \pm 3.3 \mathrm{~mm} \mathrm{Hg}(p<0.003)$ in the COVID and anaesthesia groups, respectively. In the COVID group, $\mathrm{PACO}_{2}$ showed the lowest dispersion $(-7$ to $+6 \mathrm{~mm} \mathrm{Hg})$ and better correlation with $\mathrm{PaCO}_{2}\left(\mathrm{R}^{2}=0.92\right)$. The $\mathrm{PACO}_{2}$ had a sensitivity of 0.81 and a specificity of 0.93 for identifying hypercapnic patients $\left(\mathrm{PaCO}_{2}>50 \mathrm{~mm} \mathrm{Hg}\right)$. Conclusions: Measuring end-tidal $\mathrm{PCO}_{2}$ after prolonged inspiratory time reduced the $\mathrm{PaCO}_{2}-\mathrm{PetCO}$ gradient to the point of obtaining values close to $\mathrm{PaCO}_{2}$. This measure identified hypercapnic patients in both intensive care and during anaesthesia.
\end{abstract}

Keywords: carbon dioxide monitoring; hypercapnia detection; COVID-19; ARDS; mechanical ventilation; $\mathrm{CO}_{2}$ gradient

\section{Introduction}

Lung involvement during SARS-CoV-2 infection frequently dominates the clinical picture of severe forms with both interstitial pneumonia related to the release of proinflammatory cytokines and vascular obstruction of thromboembolic origin [1]. According to international recommendations for Acute Respiratory Distress Syndrome (ARDS) management, protective ventilation is the rule. This practice often induces hypercapnia and requires regular checks of arterial $\mathrm{CO}_{2}$ pressure $\left(\mathrm{PaCO}_{2}\right)$ to adjust the level of ventilation.

In healthy anaesthetised patients, the monitoring of end-tidal $\mathrm{CO}_{2}$ pressure $\left(\mathrm{PetCO}_{2}\right)$ is mandatory even if it underestimates the $\mathrm{PaCO}_{2}$, with a gradient around $4.5-13 \mathrm{~mm}$ $\mathrm{Hg}$ [2]. Lung diseases are associated with pulmonary heterogeneity, and the $\mathrm{PaCO}_{2}-$ PetCO $\mathrm{O}_{2}$ gradient rises in unpredictable proportions [3-8]. Therefore, the $\mathrm{PetCO}_{2}$ value cannot be taken as a good estimate of alveolar $\mathrm{PCO}_{2}$ and hence cannot be used as an 
estimate of $\mathrm{PaCO}_{2}$. In previous studies in patients with acute lung injury, longer inspiratory time without a change in respiratory rate enhanced $\mathrm{CO}_{2}$ exchange [8]. During controlled ventilation in adults, the "expiratory plateau" is usually flat, but several factors, such as age and pulmonary disease, are associated with an increase in the slope of the "expiratory plateau". A prolonged expiration manoeuvre improves the prediction of $\mathrm{PaCO}_{2}$ from end-tidal $\mathrm{PCO}_{2}$ [9].

Our hypotheses were that end-tidal $\mathrm{PCO}_{2}$ measured immediately after an inspiratory time $\left(\mathrm{PACO}_{2}\right)$ prolonged by an inspiratory pause or recruitment manoeuvre could improve the estimation of $\mathrm{PaCO}_{2}$ and identify severe hypercapnia during mechanical ventilation in COVID ARDS patients or in patients anaesthetised for major surgery.

\section{Methods}

This study complied with the National Medical Ethics Regulation and was approved by the institution's Clinical Research Commission on May 2020. Patients or relatives received information that their anonymous data would be used for research purposes and did not object.

\subsection{Study Design}

This study was prospective and observational, involving routine care of a unicentric cohort, and conducted at Gustave Roussy, Villejuif, France, in both the ICU and operating theatre. Included were patients with a COVID-19 diagnosis hospitalised for ARDS (COVID group), according to the Berlin definition [10], and patients anaesthetised for major cancer surgery requiring invasive arterial monitoring (anaesthesia group). Patients under protective mechanical ventilation were deeply anaesthetised, with or without muscle relaxation. Increased inspiratory time was used in routine care in two situations: recruitment manoeuvre or prolongation of end-inspiratory pause to measure static compliance. In both groups, measurements were performed only if a bad tolerance of apnoea or recruitment was not predicted because of haemodynamic conditions, and if it would not hinder the surgeon.

\subsection{Protocol}

In both groups, a $10 \mathrm{~s}$ (arbitrarily fixed) period of apnoea was obtained using either the end-inspiratory pause function for static compliance evaluation or an automatic recruitment manoeuvre on the intensive care respirator (Evita) or Perseus anaesthesia respirator. With the Zeus anaesthesia respirator, the manoeuvre consisted of sustained manual inflation of the anaesthesia reservoir bag to a peak inspiratory pressure of $30 \mathrm{~cm} \mathrm{H}_{2} \mathrm{O}$ for $10 \mathrm{~s}$. The fraction of inspired oxygen concentration $\left(\mathrm{FiO}_{2}\right)$ was not changed during the procedures. Expiration time was set to $4 \mathrm{~s}$ by adjusting the respiratory rate to 10 cycles per minute, and an I:E ratio around 1:2, to obtain an expiratory plateau on $\mathrm{CO}_{2}$ recording. $\mathrm{PCO}_{2}$ was measured at the end of the $4 \mathrm{~s}$ expiration following the inspiratory pause or recruitment manoeuvre $\left(\mathrm{PACO}_{2}\right)$.

The same investigator carried out all measurements, using a side-stream $\mathrm{CO}_{2}$ sensor, to ensure their comparability.

An arterial blood gas measurement was collected prior to each measurement of $\mathrm{PACO}_{2}$, to calculate the $\mathrm{PaCO}_{2}-\mathrm{PetCO}_{2}$ and the $\mathrm{PaCO}_{2}-\mathrm{PACO}_{2}$ gradients and the $\mathrm{PaO}_{2} / \mathrm{FiO}_{2}$ ratio. All patients already needed arterial catheters: none were placed expressly for the study.

As the patients' respiratory and haemodynamic status varied over time, several measurements could be conducted for the same patient.

\subsection{Other Collected Data}

$\mathrm{FiO}_{2}$, basal $\mathrm{EtCO}_{2}$, tidal volume (Vt), respiratory rate (RR), inspiratory plateau pressure (Pplate), settled positive end expiratory pressure (PEEP), central temperature, and when available, level of muscle relaxation (T4/T1), haemodynamic profile including the heart rate $(\mathrm{bpm})$, mean arterial pressure $(\mathrm{mm} \mathrm{Hg})$, and norepinephrine dose (milligrams per hour), were recorded for each measurement. 


\subsection{Statistical Analysis}

Data are presented as mean values \pm standard deviations. $\mathrm{PaCO}_{2}$ values were temperature-corrected, according to the Siggaard-Andersen equation [11]. The normal distributions of $\mathrm{PetCO}_{2}, \mathrm{PACO}_{2}$, and $\mathrm{PaCO}_{2}$ data were assessed using the Q-Q plot method.

When $\mathrm{PACO}_{2}$ was available from both the inspiratory pause and recruitment, the first measurement was considered for gradient analyses. Indeed, a residual effect of the first recruitment may bias the second measurement.

A paired, two-tailed Student's $t$-test was used to compare the different values of $\mathrm{PCO}_{2}$. Correlation coefficients were obtained using the Pearson method to assess the correlation between pairs of $\mathrm{PaCO}_{2}, \mathrm{PetCO}_{2}$, and $\mathrm{PACO}_{2} . \mathrm{PaCO}_{2}-\mathrm{PetCO}_{2}, \mathrm{PaCO}_{2}-\mathrm{PACO}_{2}$, and $\mathrm{PACO}_{2}-\mathrm{PetCO}_{2}$ gradient data were compared using a two-tailed unpaired $t$-test.

Bland-Altman plots were used to test for paired $\mathrm{PetCO}_{2}, \mathrm{PACO}_{2}$, and $\mathrm{PaCO}_{2}$ agreement and reported with the $95 \%$ and $99 \%$ confidence intervals, for the separate and combined groups.

The statistical performance of $\mathrm{PACO}_{2}$ to detect normocapnia and hypercapnia was calculated for different thresholds of $\mathrm{PACO}_{2}$. It was calculated for the separate and combined groups.

All statistical results were considered significant if the $p$-value was less than 0.05. All calculations were performed using Microsoft Excel data processing software (2019 version).

\section{Results}

\subsection{Population}

From 8 April to 28 May 2020, $67 \mathrm{PACO}_{2}$ were obtained for 34 patients ( 35 measures in 7 patients in the COVID group; 32 measures in 27 patients in the anaesthesia group).

Table 1 shows demographic data and baseline characteristics of the study day. Data were similar, except for $\mathrm{PaCO}_{2}$, with more hypercapnia in the COVID group (21 vs. 10), as expected. The COVID group presented worse pulmonary characteristics, with a lower compliance (24 vs. $71 \mathrm{~mL} \mathrm{~cm} \mathrm{H} \mathrm{O}^{-1}$ in the anaesthesia group), and a lower $\mathrm{PaO}_{2} / \mathrm{FiO}_{2}$ ratio (264 vs. $337 \mathrm{~mm} \mathrm{Hg}$ ).

Table 1. Patient characteristics.

\begin{tabular}{|c|c|c|}
\hline & COVID & Anaesthesia \\
\hline Measure $(n)$ & 35 & 32 \\
\hline$\%$ male $(\mathrm{M} / \mathrm{F}$ ratio $)$ & $0.29(2 / 5)$ & $0.41(11 / 16)$ \\
\hline Mean Age (years) (range) & $65(59-73)$ & $59(23-78)$ \\
\hline \multicolumn{3}{|l|}{ Ventilator $(n)$} \\
\hline Evita & $20(5)$ & 0 \\
\hline Perseus & $12(2)$ & $30(24)$ \\
\hline Zeus & 0 & $5(3)$ \\
\hline \multicolumn{3}{|l|}{ Type of manoeuvre $(n)$} \\
\hline Increased inspiratory pause & 35 & 27 \\
\hline Recruitment & 0 & 5 \\
\hline Heart rate (bpm) (SD) & $82(13)$ & $78(13)$ \\
\hline MAP (mm Hg) (SD) & $81(13)$ & $78(14)$ \\
\hline Norepinephrine $\left(\mathrm{mg} \mathrm{h}^{-1}\right)$ & $0.21(0.46)$ & $0.24(0.88)$ \\
\hline Temperature $\left({ }^{\circ} \mathrm{C}\right)(\mathrm{SD})$ & $37(0.69)$ & $36(0.71)$ \\
\hline $\mathrm{PaCO}_{2}(\mathrm{~mm} \mathrm{Hg})(\mathrm{SD})$ & $49.3(11)$ & $42.2(5.0) *$ \\
\hline \multicolumn{3}{|l|}{$\mathrm{PaCO}_{2}(n)$} \\
\hline$\leq 35 \mathrm{~mm} \mathrm{Hg}$ & 1 & 3 \\
\hline 35 to $\leq 45 \mathrm{~mm} \mathrm{Hg}$ & 13 & 19 \\
\hline$\geq 45 \mathrm{~mm} \mathrm{Hg}$ & 21 & 10 \\
\hline Compliance $\left(\mathrm{mL} \mathrm{cm} \mathrm{H} \mathrm{O}_{2} \mathrm{O}^{-1}\right)$ & $24(9.8)$ & $72(86) *$ \\
\hline $\mathrm{PaO}_{2} / \mathrm{FiO}_{2}(\mathrm{~mm} \mathrm{Hg})(\mathrm{SD})$ & $224(53)$ & $367(110) *$ \\
\hline
\end{tabular}

MAP, mean arterial pressure; $\mathrm{PaCO}_{2}$, arterial carbon dioxide pressure; compliance $=\mathrm{Vt} /($ Pplate-PEP $)$ : $\mathrm{Vt}$, tidal volume; Pplate, plate pressure; PEP, positive end pressure. ${ }^{*}, p<0.05$ versus COVID group. 
In the COVID group, only 29 basal $\mathrm{PetCO}_{2}$ values were available, due to an initial protocol breach (6 missing data for 2 patients). No $\mathrm{PaCO}_{2}$ and no $\mathrm{PACO}_{2}$ values were missing. Five patients were ventilated using an Evita intensive care respirator (corresponding to twelve measurements), and two patients by use of a Perseus anaesthesia respirator, due to a shortage of Evita respirators in the COVID context. In the anaesthesia group, no $\mathrm{PetCO}_{2}$, $\mathrm{PACO}_{2}$, or $\mathrm{PaCO}_{2}$ values were missing.

\subsection{Student's t-Tests}

PetCO $\mathrm{O}_{2}$ underestimated $\mathrm{PaCO}_{2}$ in both groups, with a mean level of $\Delta$ (a-et) $\mathrm{CO}_{2}$ of $+11 \pm 5.7 \mathrm{~mm} \mathrm{Hg}(95 \% \mathrm{CI} 8.8-13)$ and $+5.7 \pm 3.4 \mathrm{~mm} \mathrm{Hg}(4.4-6.9)$ in the COVID and anaesthesia group, respectively ( $p<0.001$ for both). Increased inspiratory pause or recruitment manoeuvres significantly reduced the gradient to $-1.2 \pm 3.3 \mathrm{~mm} \mathrm{Hg}(-2.3$ to $-0.05)(p=0.043)$ in the COVID group, and $-1.9 \pm 3.3 \mathrm{~mm} \mathrm{Hg}(-3.1$ to -0.07$)(p<0.003)$ in the anaesthetised patients, with no significant difference between the two groups. Table 2.

Table 2. Mean $\mathrm{PCO}_{2}(\mathrm{~mm} \mathrm{Hg}$ ), and Student's t-test for comparison of paired values in the COVID group, the anaesthesia group, and the combined groups.

\begin{tabular}{cccccccccc}
\hline Gradient & \multicolumn{3}{c}{ COVID } & \multicolumn{3}{c}{ Anaesthesia } & \multicolumn{3}{c}{ Combined } \\
\hline & Mean & SD & $\boldsymbol{p}$-Value & Mean & SD & $p$-Value & Mean & SD & $p$-Value \\
\hline $\mathrm{PaCO}_{2}$ & 49 & 11 & & 42 & 5.0 & & 46 & 5.1 & 7.3 \\
$\mathrm{PetCO}_{2}$ & 39 & 9 & & 37 & 4.0 & & 38 & 4.6 & $<.4$ \\
$\mathrm{PACO}_{2}$ & 51 & 11 & & 44 & 4.7 & & $<0.001$ \\
$\mathrm{D}($ a-et)CO & +11 & 5.7 & $<0.001$ & +5.7 & 3.4 & $<0.001$ & +8.2 & $<.3$ & $<0.001$ \\
$\mathrm{D}(\mathrm{a}-\mathrm{A}) \mathrm{CO}_{2}$ & -1.2 & 3.3 & 0.043 & -1.9 & 3.3 & $<0.003$ & -1.5 & 3.3 \\
\hline
\end{tabular}

Both $\mathrm{PetCO}_{2}$ and $\mathrm{PACO}_{2}$ showed statistically significant linear correlation with $\mathrm{PaCO}_{2}$ for the two groups. In both the separate groups and combined groups, increased inspiratory pause or recruitment manoeuvres improved this correlation. COVID-PACO ${ }_{2}$ showed the best correlation $\left(R^{2}=0.92\right)$.

\subsection{Bland-Altman Dispersion}

The Bland-Altman diagram for $\Delta$ (a-et) $\mathrm{CO}_{2}$ confirmed the poor estimation of $\mathrm{PaCO}_{2}$ by $\mathrm{PetCO}_{2}$. Considering all patient data, all but two values were within a large $95 \%$ confidence interval $(-2$ to +19$)$, and the gradient increased with $\mathrm{PaCO}_{2}$, with great imprecision beyond $50 \mathrm{~mm} \mathrm{Hg}$ (Figure 1). Increased inspiratory pause or recruitment manoeuvre induced a decrease in $\Delta$ (a-A) $\mathrm{CO}_{2}$, with a lower dispersion from -8 to $+8 \mathrm{~mm} \mathrm{Hg}$. All but one value (from the anaesthesia group) were in the $99 \%$ confidence interval around the mean of the differences. These findings were verified when considering the separate groups (Figure 2).

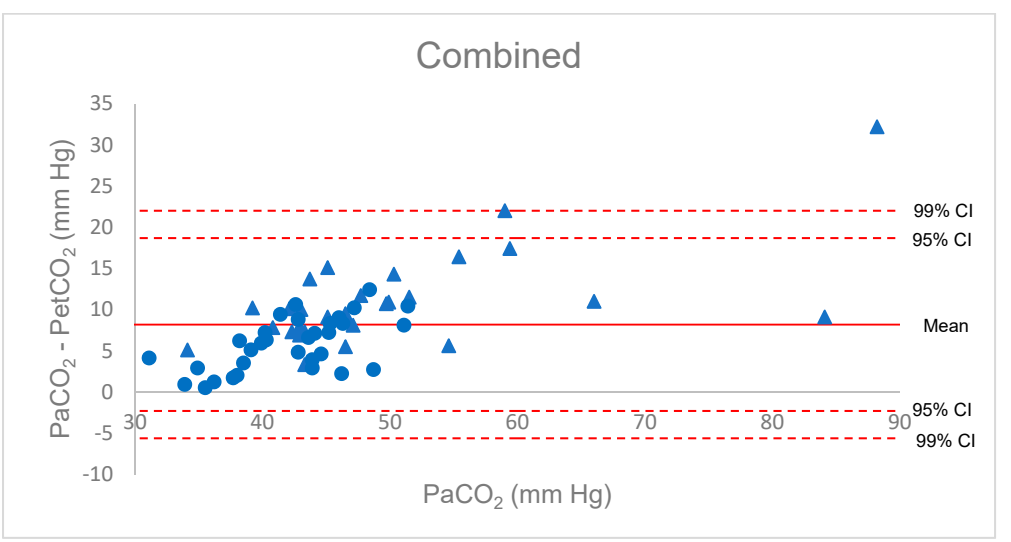

Figure 1. Bland-Altman diagram for the $\mathrm{P}(\mathrm{a}-\mathrm{et}) \mathrm{CO}_{2}$ gradient, combined group. Red triangles: COVID patients; blue circles: anaesthesia patients. 

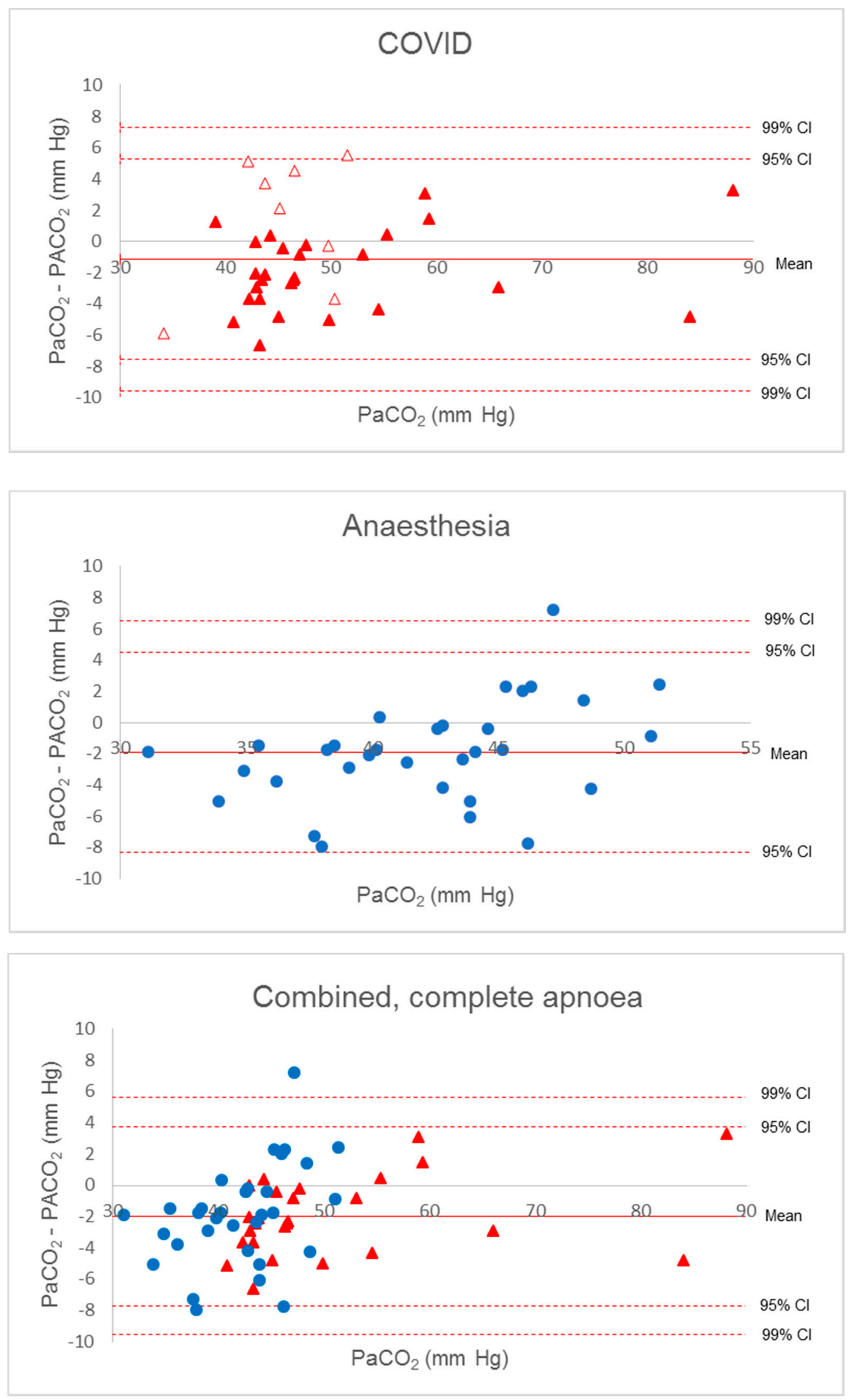

Figure 2. Bland-Altman diagram for $\mathrm{P}(\mathrm{a}-\mathrm{A}) \mathrm{CO}_{2}$ gradient. Solid red triangles, complete apnoea COVID patients; empty red triangles, incomplete apnoea COVID patient; blue circles, anaesthesia patients. 
Five measurements in the COVID group had a gradient higher than $+2 \mathrm{~mm} \mathrm{Hg}$ associated with suspected respiratory movements identified on the respiratory flow curves. Keeping only the measurements on apnoeic patients, the average and $99 \%$ confidence interval of $\Delta(\mathrm{a}-\mathrm{A}) \mathrm{CO}_{2}$ decreased slightly (mean $-2.1 \pm 2.5 \mathrm{~mm} \mathrm{Hg}(-3.1$ to -1.0$)$ ).

All patients with a $\mathrm{PACO}_{2}$ greater than $50 \mathrm{~mm} \mathrm{Hg}$ were hypercapnic, with a $\mathrm{PaCO}_{2}$ higher than $45 \mathrm{~mm} \mathrm{Hg}$. For both COVID and anaesthetised patients, the $\mathrm{PACO}_{2}$ threshold of $48 \mathrm{~mm} \mathrm{Hg}$ yielded the best performance in identifying hypercapnic patients, with Sensitivity $(\mathrm{Se})=0.68$, Specificity $(\mathrm{Sp})=0.92$, Positive Predictive Value $(\mathrm{PPV})=0.88$, Negative Predictive Value $(\mathrm{NPV})=0.77$, positive Likelihood Ratio $(\mathrm{LR}+)=8.1$, and negative Likelihood Ratio $(\mathrm{LR}-)=0.35$. The global performance improved in the COVID group, with $\mathrm{Se}=0.81, \mathrm{Sp}=0.93, \mathrm{PPV}=0.94, \mathrm{NPV}=0.77, \mathrm{LR}+=11$, and $\mathrm{LR}-=0.21$.

\section{Discussion}

Measuring $\mathrm{PCO}_{2}$ at the end of expiration following a recruitment manoeuvre or an inspiratory pause significantly decreased the gradient $\triangle$ (a-et) $\mathrm{CO}_{2}$ in both COVID and anaesthetised patients. The correlation between $\mathrm{PACO}_{2}$ and $\mathrm{PaCO}_{2}$ was better than the correlation between $\mathrm{PetCO}_{2}$ and $\mathrm{PaCO}_{2}$, especially in the COVID group. The measurement of $\mathrm{PACO}_{2}$ after inspiratory pause is completely non-invasive and does not require the patient to disconnect. It nevertheless justifies hygiene precautions such as those commonly observed during the management of suspected, probable, and confirmed cases of COVID-19 [12].

In the presence of correct measurement conditions, the absence of leakage and a respiratory rate $<30$ per minute, $\mathrm{PetCO}_{2}$ allows the estimation of $\mathrm{PaCO}_{2}$ in healthy subjects in spontaneous ventilation [13]. Under anaesthesia, especially in mechanical ventilation, the $\Delta$ (a-et) $\mathrm{CO}_{2}$ cannot be overlooked. This gradient varies from patient to patient and increases with age, smoking, ASA class, lung disease (especially in cases of pulmonary embolism), and bradycardia. $\Delta$ (a-et) $\mathrm{CO}_{2}$ is not stable during anaesthesia, ranging from 4.5 to $13 \mathrm{~mm} \mathrm{Hg}$ [2,14].

In the ARDS, the $\triangle$ (a-et) $\mathrm{CO}_{2}$ tends to increase with lung heterogeneity, as shown by Yousuf and colleagues in 2017: a greater gradient in moderate vs. mild ARDS was reported but no significant difference was found in severe vs. moderate ARDS [15]. A possible explanation could be that severe ARDS was associated with pulmonary hypertension and lower cardiac output, increasing dead-space areas that attenuate the gradient.

Many different methods have been used to estimate the $\mathrm{PaCO}_{2}$. PetCO $\mathrm{CH}_{2}$ presents a weak correlation in healthy lungs [14,16-20], worsening in sick lungs, with no difference in the accuracy using a main- or side-stream sensor [21,22]. In diseased lungs, results vary greatly between studies, with moderate correlations and large dispersion around the reference $\mathrm{PaCO}_{2}$ value $[8,15]$. While the measurement of transcutaneous $\mathrm{PCO}_{2}$ yields better results, its use is essentially limited to the paediatric intensive care unit [23].

Inspiratory time influences the $\mathrm{PetCO}_{2}$ value [24]. Some manoeuvres, such as a simple prolonged exhalation, have been proposed to reduce $\mathrm{P}(\mathrm{a}-\mathrm{et}) \mathrm{CO}_{2}[9]$.

Out of a series of 16 patients undergoing thoraco-abdominal oesophagectomy, Tavernier and colleagues [9] showed a decrease in the $\mathrm{P}(\mathrm{a}-\mathrm{et}) \mathrm{CO}_{2}$ gradient after prolonged expiration or prolonged expiration preceded by lung hyperinflation, from $9.8 \pm 3.0$ to $6.0 \pm 3.8$ and $4.5 \pm 3.8 \mathrm{~mm} \mathrm{Hg}$, respectively. The authors concluded, however, that due to extreme inter-individual variability, these manoeuvres did not improve $\mathrm{PetCO}_{2}$ 's assessment of $\mathrm{PaCO}_{2}$. However, $\mathrm{PetCO}_{2}$ can identify the most severe hypercapnia and hypocapnia. A PetCO 2 between 30 and $35 \mathrm{~mm} \mathrm{Hg}$ most often corresponds to normocapnia (35 to $45 \mathrm{~mm} \mathrm{Hg}$ ).

Several pathophysiological mechanisms could be involved to explain the effectiveness of our manoeuvre, as follows.

First, maintaining high pressure in the airways for a period of time allows some collapsed alveoli to open, homogenizing the distribution of the ventilation/perfusion ratio. The alveoli recruitment mechanism was evidenced by the greater decrease in the carbon 
dioxide gradient in the COVID group, demonstrated by a mean difference $\Delta(\mathrm{a}-\mathrm{A}) \mathrm{CO}_{2}-$ $\Delta$ (a-et) $\mathrm{CO}_{2}$ of -12.2 vs. $-7.5 \mathrm{~mm} \mathrm{Hg}$ in the anaesthesia group. Several studies have shown that prolongation of the inspiratory time decreases alveolar dead-space [9,25]. Diffusion of $\mathrm{CO}_{2}$ is time-dependent, and this prolongation increases the time available for alveolar gas exchange.

Second, during apnoea, increased inspiratory time allows homogenisation of $\mathrm{PCO}_{2}$ in the alveoli and between the alveoli and blood. During prolonged apnoea, alveolar $\mathrm{PCO}_{2}$ approaches pulmonary venous blood $\mathrm{PCO}_{2}$ due to the absence of alveolar gas movement. This effect has certainly contributed to the reduction of $\mathrm{CO}_{2}$ gradients.

Under ARDS conditions, tidal volume was set to $6 \mathrm{~mL} / \mathrm{kg}$ with a high respiratory rate to maintain alveolar ventilation and reduced expiratory time. This increased the consequences of inequalities in regional respiratory time constants. Hence, the $\mathrm{PetCO}_{2}$ value depended on short- and long-time constant alveoli gas mix. $\mathrm{PACO}_{2}$ tends toward the central venous $\mathrm{PCO}_{2}$ due to reduced expired volume of poorly ventilated alveoli. Setting the respiratory rate to 10 cycles per minute prior to each $\mathrm{PACO}_{2}$ measurement improved the expiration of long-time constant alveoli. The recruitment of high $\mathrm{CO}_{2}$-concentrated alveoli cumulated with the prolongation of expiration, inducing an increased expiratory $\mathrm{CO}_{2}$ peak, with $\mathrm{PACO}_{2}$ over-estimating the $\mathrm{PaCO}_{2}[26,27]$.

Late emptying of well-perfused alveoli with higher $\mathrm{CO}_{2}$ tensions and better overall ventilation/perfusion matching helped to reduce the gradient between $\mathrm{PaCO}_{2}$ and $\mathrm{PetCO}_{2}$, which became negative in some cases. Negative (a-et) $\mathrm{PCO}_{2}$ gradients have been reported in infants and children, in pregnant patients, and during exercise [11,26]. This late mechanism may play an important role.

Fletcher and Jonson have studied the $\mathrm{Vd} / \mathrm{Vt}$ ratio and $\mathrm{P}(\mathrm{a}-\mathrm{et}) \mathrm{CO}_{2}$ gradient at two levels of $\mathrm{Vt}(450$ and $750 \mathrm{~mL})$ in anaesthetised patients [28]. Increasing $\mathrm{Vt}$ and decreasing the respiratory frequency did not change the airway dead-space but decreased the alveolar dead-space ratio. This improvement with increasing $\mathrm{Vt}$ was attributed to beneficial effects on gas distribution and diffusion time. At large $\mathrm{Vt}$, the $\mathrm{P}(\mathrm{a}-\mathrm{et}) \mathrm{CO}_{2}$ gradient decreased from 4.5 to $2.5 \mathrm{~mm} \mathrm{Hg}$, with a negative gradient in some patients. It is difficult to distinguish between what amounts to an increase in inspiratory time and expiratory time. Increased inspiratory time improves the distribution of the ventilation/perfusion ratio, and increased expiratory time decreases alveolar dead-space.

Third, $\mathrm{PetCO}_{2}$ and $\mathrm{PACO}_{2}$ are measured by computer analysis of the highest point reached by the capnogram curve at the end of the expiration. The overall performance (response time) of the capnograph including the sample line may be insufficient when high respiratory frequencies are used [24,29]. It is possible that some $\mathrm{PetCO}_{2}$ values may have been underestimated due to insufficient capnograph response time relative to the respiratory rate used. Therefore, the $4 \mathrm{~s}$ extended expiration time reduced the expiratory slope and thus reduced the bias in the computer analysis of $\mathrm{PetCO}_{2}$.

Our study also had some limitations. First, the lack of hypocapnic patients does not allow us to draw conclusions about the capacity of the measurement to detect a $\mathrm{PaCO}_{2}$ less than $35 \mathrm{~mm} \mathrm{Hg}$ under such conditions. Second, some measurements were suspected to have been collected under not completely apnoeic conditions. However, the accuracy of the $\Delta(\mathrm{A}-\mathrm{a}) \mathrm{CO}_{2}$ was relatively unaffected by the inclusion or not of these measures in the Bland-Altman diagram.

Initially, the data analysis protocol did not anticipate how to deal with the $\mathrm{PACO}_{2}$ values obtained using both the inspiratory pause and recruitment methods. We chose to only consider the first of the two measures, hypothesising that the residual effect of the first might bias the interpretation of the second.

According to the Berlin definition [10], there was no severe ARDS in our study, and patients were not haemodynamically unstable. We cannot draw conclusions about the effectiveness of our methods in patients with more severe lung diseases.

To conclude, measuring $\mathrm{PCO}_{2}$ after a prolonged inspiration and expiration improves the estimation of $\mathrm{PaCO}_{2}$ from $\mathrm{PetCO}_{2}$ and the identification of hypercapnic patients me- 
chanically ventilated during anaesthesia and for COVID-related ARDS. Measuring endtidal $\mathrm{PCO}_{2}$ after prolonged inspiratory time reduced the $\mathrm{PaCO}_{2}-\mathrm{PetCO}_{2}$ gradient to the point of obtaining values close to $\mathrm{PaCO}_{2}$. This non-invasive measure seems particularly interesting when using small $\mathrm{Vt}$ in the protected ventilation. However, further studies are needed to explore its usefulness in other conditions, such as in brain-injured patients, severe ARDS, and/or hypocapnic patients.

Author Contributions: A.S. (Arthur Salomé) had full access to all of the data in the study and takes responsibility for the acquisition and integrity of the data and the accuracy of the data analysis; A.S. (Arthur Salomé) and J.-L.B. contributed to the conception and design of the study; A.S. (Arthur Salomé) and J.-L.B. contributed to the analysis and interpretation of the data; A.S. (Arthur Salomé) wrote the first draft of the manuscript; A.S. (Arthur Salomé), J.-L.B., and A.S. (Annabelle Stoclin) critically revised the manuscript; C.M. and P.S. critically revised the manuscript; A.S. (Arthur Salomé) was responsible for the statistical analysis. All authors approved the final version of the manuscript.

Funding: This research received no external funding.

Institutional Review Board Statement: The study was conducted according to the guidelines of the Declaration of Helsinki, and approved by the Institutional Review Board of Gustave Roussy Hopsital. (20-05-20).

Informed Consent Statement: Patients consent was waived as no change in current practice was performed.

Data Availability Statement: Data available on demand (arthur.salome1995@gmail.com).

Conflicts of Interest: The authors declare that they have no conflict of interest.

\section{References}

1. Maiese, A.; Manetti, A.C.; La Russa, R.; Di Paolo, M.; Turillazzi, E.; Frati, P.; Fineschi, V. Autopsy findings in COVID-19-related deaths: A literature review. Forensic Sci. Med. Pathol. 2021, 17, 279-296. [CrossRef] [PubMed]

2. Raemer, D.B.; Francis, D.; Philip, J.H.; Gabel, R.A. Variation in $\mathrm{PCO}_{2}$ between arterial blood and peak expired gas during anesthesia. Anesth. Analg. 1983, 62, 1065-1069. [CrossRef]

3. Belpomme, V.; Ricard-Hibon, A.; Devoir, C.; Dileseigres, S.; Devaud, M.L.; Chollet, C.; Marty, J. Correlation of arterial PCO 2 and $\mathrm{PETCO}_{2}$ in prehospital controlled ventilation. Am. J. Emerg. Med. 2005, 23, 852-859. [CrossRef]

4. Strang, C.M.; Hachenberg, T.; Fredén, F.; Hedenstierna, G. Development of atelectasis and arterial to end-tidal $\mathrm{PCO}_{2}$-difference in a porcine model of pneumoperitoneum. Br. J. Anaesth. 2009, 103, 298-303. [CrossRef] [PubMed]

5. Law, G.T.S.; Wong, C.Y.; Kwan, C.W.; Wong, K.Y.; Wong, F.P.; Tse, H.N. Concordance between side-stream end-tidal carbon dioxide and arterial carbon dioxide partial pressure in respiratory service setting. Hong Kong Med. J. 2009, 15, 440-446.

6. Defilippis, V.; D’Antini, D.; Cinnella, G.; Dambrosio, M.; Schiraldi, F.; Procacci, V. End-tidal arterial $\mathrm{CO}_{2}$ partial pressure gradient in patients with severe hypercapnia undergoing noninvasive ventilation. Open Access Emerg. Med. 2013, 5, 1-7. [CrossRef] [PubMed]

7. Hardman, J.G.; Aitkenhead, A.R. Estimating alveolar dead space from the arterial to end-tidal $\mathrm{CO}_{2}$ gradient: A modeling analysis. Anesth. Analg. 2003, 97, 1846-1851. [CrossRef] [PubMed]

8. Long, B.; Koyfman, A.; Vivirito, M.A. Capnography in the Emergency Department: A Review of Uses, Waveforms, and Limitations. J. Emerg. Med. 2017, 53, 829-842. [CrossRef]

9. Tavernier, B.; Rey, D.; Thevenin, D.; Triboulet, J.P.; Scherpereel, P. Can prolonged expiration manoeuvres improve the prediction of arterial $\mathrm{PCO}_{2}$ from end-tidal $\mathrm{PCO}_{2}$ ? Br. J. Anaesth. 1997, 78, 536-540. [CrossRef]

10. ARDS Definition Task Force; Ranieri, V.M.; Rubenfeld, G.D.; Thompson, B.T.; Ferguson, N.; Caldwell, E.; Fan, E.; Camporota, L.; Slutsky, A.S. Acute respiratory distress syndrome: The Berlin Definition. JAMA 2012, 307, 2526-2533. [CrossRef]

11. Losa-Reyna, J.; Torres-Peralta, R.; Henriquez, J.J.G.; Calbet, J.A.L. Arterial to end-tidal $\mathrm{Pco}_{2}$ difference during exercise in normoxia and severe acute hypoxia: Importance of blood temperature correction. Physiol. Rep. 2015, 3, e12512. [CrossRef]

12. Fineschi, V.; Aprile, A.; Aquila, I.; Arcangeli, M.; Asmundo, A.; Bacci, M.; Cingolani, M.; Cipolloni, L.; D’Errico, S.; De Casamassimi, I.; et al. Management of the corpse with suspect, probable or confirmed COVID-19 respiratory infection-Italian interim recommendations for personnel potentially exposed to material from corpses, including body fluids, in morgue structures and during autopsy practice. Pathologica 2020, 112, 64-77. [CrossRef]

13. Liu, S.Y.; Lee, T.S.; Bongard, F. Accuracy of capnography in nonintubated surgical patients. Chest 1992, 102, 1512-1515. [CrossRef] [PubMed]

14. Casati, A.; Salvo, I.; Torri, G.; Calderini, E. Arterial to end-tidal carbon dioxide gradient and physiological dead space monitoring during general anaesthesia: Effects of patients' position. Minerva Anestesiol. 1997, 63, 177-182. 
15. Yousuf, T.; Brinton, T.; Murtaza, G.; Wozniczka, D.; Ahmad, K.; Iskandar, J.; Mehta, R.; Keshmiri, H.; Hanif, T. Establishing a gradient between partial pressure of arterial carbon dioxide and end-tidal carbon dioxide in patients with acute respiratory distress syndrome. J. Investig. Med. 2017, 65, 338-341. [CrossRef]

16. Hinkelbein, J.; Floss, F.; Denz, C.; Krieter, H. Accuracy and precision of three different methods to determine $\mathrm{PcO}_{2}\left(\mathrm{PacO}_{2} \mathrm{vs}\right.$ $\mathrm{Petco}_{2}$ vs. $\mathrm{PtcCO}_{2}$ ) during interhospital ground transport of critically ill and ventilated adults. J. Trauma Acute Care Surg. 2008, 65, 10-18. [CrossRef]

17. Nassar, B.S.; Schmidt, G.A. Estimating Arterial Partial Pressure of Carbon Dioxide in Ventilated Patients: How Valid Are Surrogate Measures? Ann. Am. Thorac. Soc. 2017, 14, 1005-1014. [CrossRef]

18. Fox, B.D.; Joyal, D.; Schlesinger, R.D.; Eisenberg, M.J.; Langleben, D. Evaluation of the Microstat ${ }^{\mathrm{TM}}$ sublingual $\mathrm{PCO}_{2}$ monitor in ambulatory patients. J. Clin. Monit. Comput. 2016, 30, 77-80. [CrossRef] [PubMed]

19. Robbins, P.A.; Conway, J.; Cunningham, D.A.; Khamnei, S.; Paterson, D.J. A comparison of indirect methods for continuous estimation of arterial $\mathrm{PCO}_{2}$ in men. J. Appl. Physiol. 1990, 68, 1727-1731. [CrossRef] [PubMed]

20. Fierstra, J.; Machina, M.; Battisti-Charbonney, A.; Duffin, J.; Fisher, J.A.; Minkovich, L. End-inspiratory rebreathing reduces the end-tidal to arterial $\mathrm{PCO}_{2}$ gradient in mechanically ventilated pigs. Intensive Care Med. 2011, 37, 1543-1550. [CrossRef]

21. Chan, K.L.; Chan, M.T.V.; Gin, T. Mainstream vs. sidestream capnometry for prediction of arterial carbon dioxide tension during supine craniotomy. Anaesthesia 2003, 58, 149-155. [CrossRef]

22. Kasuya, Y.; Akça, O.; Sessler, D.I.; Ozaki, M.; Komatsu, R. Accuracy of postoperative end-tidal Pco 2 measurements with mainstream and sidestream capnography in non-obese patients and in obese patients with and without obstructive sleep apnea. Anesthesiology 2009, 111, 609-615. [CrossRef]

23. Duyu, M.; Çağlar, Y.M.; Karakaya, Z.; Aslan, M.U.; Yılmaz, S.; Leblebici, A.N.; Bektaş, A.D.; Bahar, M.; Yersel, M.N. Comparison of arterial $\mathrm{CO}_{2}$ estimation by end-tidal and transcutaneous $\mathrm{CO}_{2}$ measurements in intubated children and variability with subject related factors. J. Clin. Monit. Comput. 2021, 35, 101-111. [CrossRef]

24. From, R.P.; Scamman, F.L. Ventilatory frequency influences accuracy of end-tidal $\mathrm{CO}_{2}$ measurements. Analysis of seven capnometers. Anesth. Analg. 1988, 67, 884-886. [CrossRef] [PubMed]

25. Sturesson, L.W.; Malmkvist, G.; Allvin, S.; Collryd, M.; Bodelsson, M.; Jonson, B. An appropriate inspiratory flow pattern can enhance $\mathrm{CO}_{2}$ exchange, facilitating protective ventilation of healthy lungs. Br. J. Anaesth. 2016, 117, 243-249. [CrossRef]

26. Bhavani-Shankar, K. Negative arterial to end-tidal $\mathrm{CO}_{2}$ gradients in children. Can. J. Anaesth. 1994, 41, 1125-1126. [CrossRef]

27. Campbell, F.A.; McLeod, M.E.; Bissonnette, B.; Swartz, J.S. End-tidal carbon dioxide measurement in infants and children during and after general anaesthesia. Can. J. Anaesth. 1994, 41, 107-110. [CrossRef]

28. Fletcher, R.; Jonson, B. Deadspace and the single breath test for carbon dioxide during anaesthesia and artificial ventilation. Effects of tidal volume and frequency of respiration. Br. J. Anaesth. 1984, 56, 109-119. [CrossRef] [PubMed]

29. Jaffe, M.B. Respiratory Gas Analysis-Technical Aspects. Anesth. Analg. 2018, 126, 839-845. [CrossRef] [PubMed] 